\title{
Ultrafast Vibrational Dynamics of CO Ligands on RuTPP/Cu(110) under Photodesorption Conditions
}

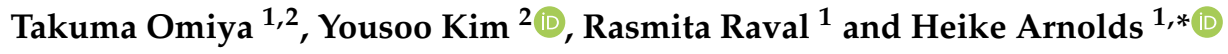 \\ 1 Surface Science Research Centre and Department of Chemistry, University of Liverpool, \\ Liverpool L69 3BX, UK; 0038takuma@gmail.com (T.O.); raval@liverpool.ac.uk (R.R.) \\ 2 Surface and Interface Science Laboratory, RIKEN, Wako, Saitama 351-0198, Japan; ykim@riken.jp \\ * Correspondence: Heike.Arnolds@liverpool.ac.uk; Tel.: +44-151-794-3543
}

Received: 16 December 2018; Accepted: 3 February 2019; Published: 7 February 2019

\begin{abstract}
We have studied CO coordinated to ruthenium tetraphenylporphyrin (RuTPP)/Cu(110) and directly adsorbed to $\mathrm{Cu}(110)$, using femtosecond pump-sum frequency probe spectroscopy, to alter the degree of electron-vibration coupling between the metal substrate and $\mathrm{CO}$. We observe the facile femtosecond laser-induced desorption of $\mathrm{CO}$ from $\mathrm{RuTPP} / \mathrm{Cu}(110)$, but not from $\mathrm{Cu}(110)$. A change in the vibrational transients, in the first few picoseconds, from a red- to blue-shift of the $\mathrm{C}-\mathrm{O}$ stretching vibration under photodesorption conditions, was also observed. This drastic change can be explained, if the cause of the $\mathrm{C}-\mathrm{O}$ frequency redshift of $\mathrm{Cu}(110)$ is not the usually-assumed anharmonic coupling to low frequency vibrational modes, but a charge transfer from hot electrons to the $\mathrm{CO} 2 \pi^{*}$ state. This antibonding state shifts to higher energies on RuTPP, removing the $\mathrm{C}-\mathrm{O}$ redshift and, instead, reveals a blueshift, predicted to arise from electron-mediated coupling between the coherently excited internal stretch and low frequency modes in the system.
\end{abstract}

Keywords: adsorbate dynamics; pump-probe spectroscopy

\section{Introduction}

Understanding adsorbate dynamics on surfaces is crucial to many phenomena, ranging from heterogeneous catalysis to sensing devices. Over the past 30 years, time-resolved vibrational and electronic spectroscopies, based on femtosecond laser pulses, have made many important contributions to our understanding, with the investigation of vibrational excitation, diffusion, desorption, and reaction [1-3]. Due to the high absorption cross-section of metal surfaces, compared to most adsorbates, the photon energy is first deposited in the metal electrons followed by energy transfer to phonons and the adsorbate. The interpretation of spectra, therefore, generally rests on the fact that hot electrons exist for around 1 ps before equilibration with phonons. Thus, any sub-picosecond response is thought to represent a signature of nonadiabatic dynamics, where energy is directly transferred between hot electrons and the adsorbate vibrational modes, while changes on the tens-of-picoseconds timescale relate to hot phonons and adiabatic dynamics.

Due to the large energy difference between the typically observed internal stretching (IS) mode of $\mathrm{CO}$ or $\mathrm{NO}$ and the energy scale of hot electrons, the generally accepted model involves direct energy transfer between hot electrons and low energy vibrational modes, which, in turn, couple anharmonically to the observed high energy mode. The majority of studies have focused on the vibrational dynamics of $\mathrm{CO}$, which, so far, have been generally attributed to coupling between hot electrons and the frustrated rotation (FR) mode; for example, on $\mathrm{Ru}(001)$ [4] and $\mathrm{Pt}(111)$ [5]. The origin of the observed redshift of the $\mathrm{C}-\mathrm{O}$ stretch, while the surface electrons are hot, is thought to be caused by excitation of the frustrated translational (FT) mode, which is indirectly heated through the frustrated rotation, as modeled by Ueba and Persson [6,7]. The FR is then thought to be responsible 
for transferring the molecule into the transition state for diffusion [8] or desorption [9]. This model was further supported by ultrafast photoelectron spectroscopy, which suggested that the CO-Ru bond coordination increases in the first picosecond after pump excitation, due to the excitation of the FR mode [10]. A phase-resolved measurement of the pump-perturbed free-induction decay of $\mathrm{CO} / \mathrm{Pt}(111)$, in addition, proposed excitation of the CO-metal (M) mode, by noticing that the redshift of the $\mathrm{C}-\mathrm{O}$ frequency was followed by a rapid reverse (blue) shift in the first picosecond, under desorption conditions [11]. Phase-resolved sum frequency measurements of $\mathrm{CO} / \mathrm{Cu}(100)$ were even used to extract different mode temperatures for IS and FR modes [12].

In recent years, theory has made great strides in including non-adiabatic effects in adsorbate dynamics on metals [13], and is now beginning to challenge this picture of energy transfer with the surprising result that phonons contribute significantly to the vibrational and desorption dynamics on sub-picosecond timescales [14-16]. Experimental approaches have focused on modifying the degree of coupling between hot electrons and high energy vibrational modes, by studying CO adsorbed on nanoparticles [17,18] and addressing the influences of coverage [19], adsorption site [20], and surface temperature [21].

Here, we attempt to further our understanding of nonadiabatic coupling between electrons and vibrations and modify the vibrational dynamics by decoupling $\mathrm{CO}$ from the bulk metal through coordination to a metalloporphyrin on a metal substrate. The interest in these systems stems from the profound influence which small ligands can have on the adsorbed metalloporphyrin's electronic and magnetic properties. For example, coordination of $\mathrm{CO}$ to bulk ruthenium tetraphenylporphyrin (RuTPP) increases the RuTPP excited state lifetime 100 times, by switching the relaxation pathway from a singlet to a triplet state [22]. For metalloporphyrins adsorbed on metal substrates, coordination of NO decouples the metal ion from the metal substrate, partly reversing changes in the electronic structure caused by interaction with the underlying metal and, in addition, changes the spin state of the metal ions [23]. A recent inelastic tunneling study of CO, coordinated to RuTPP adsorbed on $\mathrm{Cu}(110)$, revealed that $\mathrm{CO}$ desorption by injection of holes from a scanning tunneling microscope tip proceeds in an unusual two-carrier process, which could be related to $\mathrm{CO}$ decoupling the $\mathrm{Ru}$ ion from the copper surface [24]. Existing time-resolved studies have only been carried out on CO ligands at heme proteins. Upon absorption of photons by the heme, $\mathrm{CO}$ is photodissociated and transfers to a nearby docking site [25-27]. Ultrafast visible pump mid-IR probe measurements showed that CO rotated upon dissociation and moved to the new site in less than a picosecond [28].

Here, we investigate the nonadiabatic vibrational dynamics of $\mathrm{CO}$ from CO-RuTPP/Cu(110) under photodesorption conditions. Thermal and laser desorption are compared, showing that CO-RuTPP $/ \mathrm{Cu}(110)$ exhibits facile laser desorption, despite possessing a higher thermal desorption temperature than $\mathrm{CO} / \mathrm{Cu}(110)$. Visible pump-sum frequency probe spectroscopy reveals that coupling to hot electrons is significantly altered by introducing the RuTPP monolayer to $\mathrm{Cu}(110)$. The frequency of the $\mathrm{C}-\mathrm{O}$ stretch mode of CO-RuTPP shows a blue shift during coupling to hot electrons under photodesorption conditions. This phenomenon is more easily explained if the nonadiabatic dynamics of $\mathrm{CO} / \mathrm{Cu}(110)$ are not caused by anharmonic coupling of the internal stretch to low frequency vibrations, but instead by charge transfer to the $\mathrm{CO} 2 \pi^{*}$ state.

\section{Materials and Methods}

Sum frequency experiments were performed with an amplified $10 \mathrm{~Hz}$ femtosecond laser system (TSA-10, Spectra Physics, Santa Clara, CA, USA) inside a UHV chamber, as described previously [19]. One optical parametric amplifier (TOPAS, Light Conversion, Vilnius, Lithuania) generates $4 \mu \mathrm{J}, 200 \mathrm{fs}$ mid-IR pulses, while a second TOPAS creates a $150 \mathrm{fs}$ pump beam with wavelengths of $532 \mathrm{~nm}$, $800 \mathrm{~nm}$, or $400 \mathrm{~nm}$. The remainder is passed through an etalon (SLS Optics Ltd, Tromode, Isle of Man) to produce an upconversion pulse of about $7 \mathrm{~cm}^{-1}$ spectral width, time-shifted by $1.3 \mathrm{ps}$ to reduce the non-resonant sum frequency signal [29]. To fit resonant sum frequency data, we used a sum of Lorentzian peak shapes for $\chi^{(2)}$, convoluted with a Gaussian peak with the up-conversion pulse width. 
For pump-probe measurements, a single $\mathrm{Cu}(110)$ crystal was cleaned by $1 \mathrm{keV} \mathrm{Ar}^{+}$bombardment, followed by annealing to $600 \mathrm{~K}$. Ruthenium tetraphenylporphyrin (RuTPP, Sigma Aldrich Company $\mathrm{Ltd}$, Gillingham, UK) was used as purchased and sublimed at $500 \mathrm{~K}$ onto the $\mathrm{Cu}(110)$ surface, which was held at $300 \mathrm{~K}$ during deposition. The RuTPP coverage was estimated from TPD. The CO was dosed from the background at a substrate temperature of $100 \mathrm{~K}$. All pump-probe sum frequency spectra shown were recorded at a $100 \mathrm{~K}$ substrate temperature. Unpumped sum frequency spectra were recorded every four time-delay points, to confirm long term stability of the CO and RuTPP layer during pulsed laser irradiation. Sum frequency spectra of $\mathrm{CO}$ adsorbed on bare $\mathrm{Cu}(110)$ were acquired after dosing, while pump-probe spectra on RuTPP-covered $\mathrm{Cu}(110)$ were acquired under $10^{-8} \mathrm{mbar}$ $\mathrm{CO}$ partial pressure to replenish CO desorbing from RuTPP.

The STM image, shown in Figure 1, was acquired in a separate chamber with a low-temperature STM (Scienta Omicron Inc, Taunusstein, Germany) at $4.7 \mathrm{~K}$.

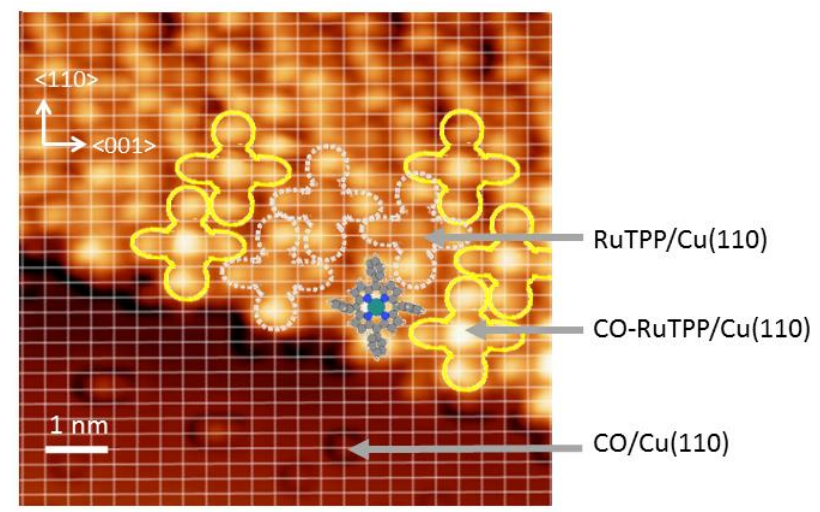

Figure 1. Scanning tunneling microscope $(\mathrm{STM})$ image $\left(8.5 \times 8.5 \mathrm{~nm}^{2}\right)$ of ruthenium tetraphenylporphyrin (RuTPP) co-adsorbed with $\mathrm{CO}$ on $\mathrm{Cu}(110)$, superimposed on the $\mathrm{Cu}(110)$ lattice lines calibrated by $\mathrm{CO} / \mathrm{Cu}(110)$. The image was obtained at $4.7 \mathrm{~K}$ with $\mathrm{V}=500 \mathrm{mV}$ and $\mathrm{I}=0.5 \mathrm{nA}$. A ball and stick model of RuTPP is overlaid on the STM image. RuTPP and CO-RuTPP are marked by white dotted and yellow solid lines, respectively. The indentations on the bare surface (at the bottom part of the image) are adsorbed CO molecules.

\section{Results}

\subsection{Thermal Versus Laser Induced Desorption}

Figure 1 shows a scanning tunneling microscope (STM) image of a low coverage of CO-RuTPP adsorbed on $\mathrm{Cu}(110)$ at $4.7 \mathrm{~K}$. The RuTPP layer forms chiral domains with Ru on a short bridge site, and with the $\lambda$ phase described by the following matrix

$$
G^{\lambda}=\left[\begin{array}{cc}
2 & 4 \\
-6 & -2
\end{array}\right]
$$

similar to the structures observed for CoTPP adsorbed on $\mathrm{Cu}(110)$ [30]. Based on the unit cell size, up to 0.05 monolayers (ML) of RuTPP molecules can adsorb on $\mathrm{Cu}(110)$. Depending on the RuTPP coverage, $\mathrm{CO}$ can also adsorb directly to $\mathrm{Cu}(110)$ at RuTPP domain boundaries, or on remaining uncovered areas.

Figure 2a shows thermal desorption spectra of $\mathrm{CO}$ from $\mathrm{RuTPP} / \mathrm{Cu}(110)$ and $\mathrm{Cu}(110)$. The mass 28 signal appears around $200 \mathrm{~K}$ from $0.1 \mathrm{ML} \mathrm{CO}$ on $\mathrm{Cu}(110)$. The desorption temperature is lower for saturated $\mathrm{CO}$ on $\mathrm{Cu}(110)$, which can be explained by repulsive dipole-dipole interactions [31]. The RuTPP pre-covered $\mathrm{Cu}(110)$ surface shows a similar desorption peak around $190 \mathrm{~K}$, which is assigned to $\mathrm{CO}$ desorption from the remaining bare parts of the $\mathrm{Cu}(110)$ surface. In addition, a new desorption peak appears around $280 \mathrm{~K}$, as marked by an arrow in Figure 2a. At this temperature, 
the resonant sum frequency signal of the $\mathrm{C}-\mathrm{O}$ stretch mode from CO-RuTPP/Cu(110) disappears, as shown in Figure 2b, and, therefore, this peak is assigned to CO desorption from the RuTPP molecules. For the surface preparation shown, the TPD integrals, compared to the CO saturation TPD integral, yield coverages of $0.04 \mathrm{ML}$ CO adsorbed on RuTPP (slightly lower than the theoretical maximum of $0.05 \mathrm{ML}$ for a perfect RuTPP layer) and 0.26 ML on $\mathrm{Cu}(110)$.
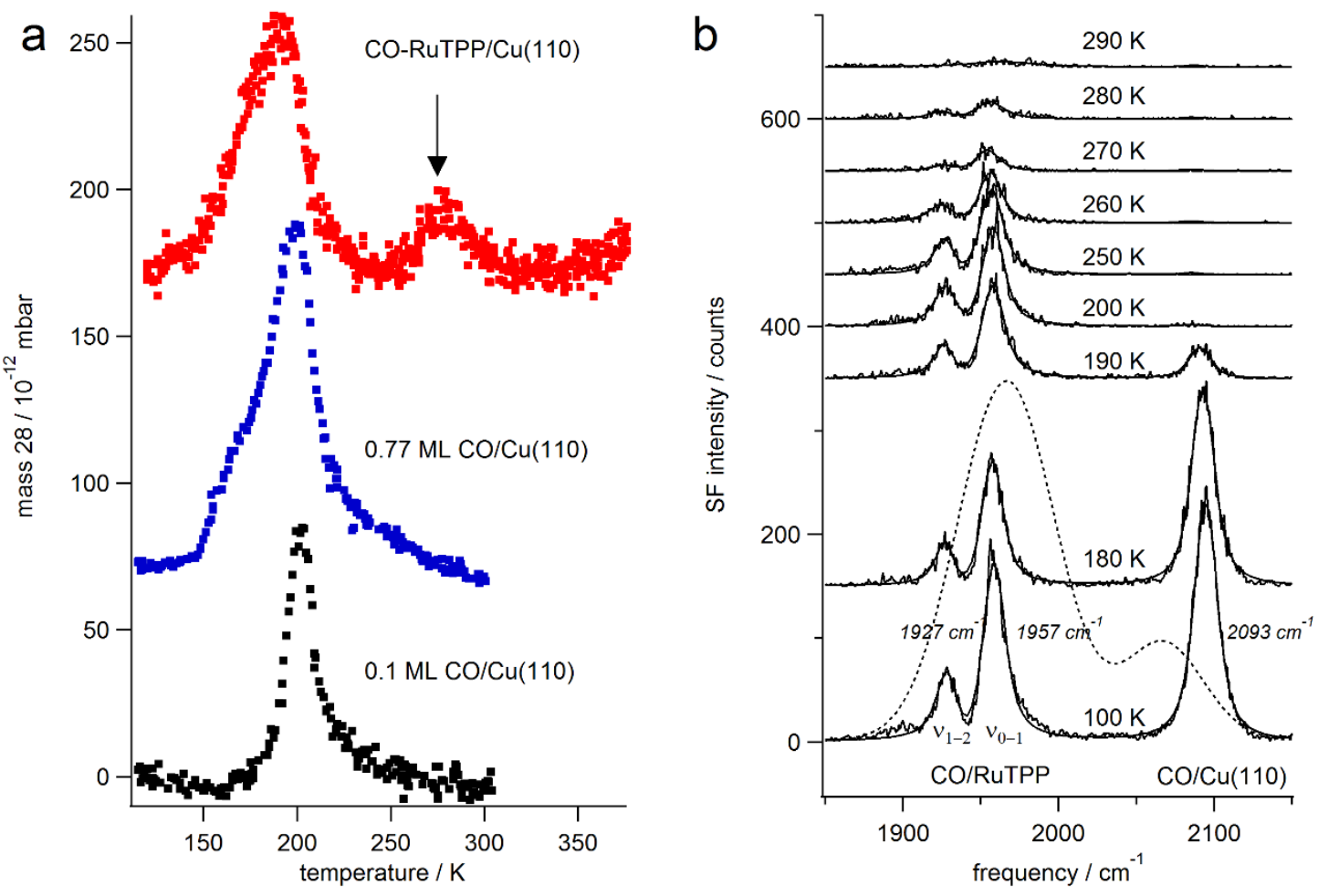

Figure 2. (a) Thermal desorption spectra of $\mathrm{CO}$ (mass 28) acquired from $\mathrm{CO} / \mathrm{Cu}(110)$ and CO-RuTPP/Cu(110), at a heating rate of $2 \mathrm{~K} / \mathrm{s}$. Spectra from $0.77 \mathrm{ML} \mathrm{CO} / \mathrm{Cu}(110)$ are scaled by 0.25 . An arrow points to the peak around $280 \mathrm{~K}$, which was assigned as $\mathrm{CO}$ desorption from $\mathrm{RuTPP} / \mathrm{Cu}(110)$; (b) Sum frequency spectra of the C-O stretch mode from CO-RuTPP/Cu(110) as a function of substrate temperature. To probe CO adsorbed on RuTPP and on bare copper patches simultaneously, the TOPAS was detuned to generate IR intensity across $200 \mathrm{~cm}^{-1}$, the IR intensity envelope is shown as a dashed line.

From the desorption spectra shown, desorption barriers of $0.54 \mathrm{eV}$ and $0.75 \mathrm{eV}$ were calculated using the Redhead equations for $\mathrm{CO} / \mathrm{Cu}(110)$ and $\mathrm{CO}-\mathrm{RuTPP} / \mathrm{Cu}(110)$, respectively, with an assumption of first order desorption and a frequency factor $v=10^{13} \mathrm{~s}^{-1}$. While the Redhead equation only provides an estimate of the desorption barrier, it is clear that $\mathrm{CO}$ is thermally more stable on RuTPP/Cu(110) than on $\mathrm{Cu}(110)$. The dissociation energy of CO-RuTPP in the gas phase has recently been determined as $1.88 \mathrm{eV}$ [32]. The thermal stability of CO-RuTPP is, therefore, reduced upon adsorption onto $\mathrm{Cu}(110)$. This can be explained by hybridization between the ruthenium and copper orbitals, as previously reported for $\mathrm{CoTPP} / \mathrm{Cu}(110)$ [30], where density functional theory (DFT) deduced a charge transfer of $1.3 \mathrm{e}^{-}$from the uppermost copper layer to the cobalt $\mathrm{d}_{\mathrm{z} 2}, \mathrm{LUMO}$, and LUMO +1 orbitals. Adsorption of RuTPP onto copper could, therefore, also increase the occupation of the ruthenium $\mathrm{d}_{\pi^{*}}$ orbital, which, in turn, would reduce the backdonation to the $\mathrm{CO} 2 \pi^{*}$ orbital and, as a result, weaken the CO-Ru bond. This, in turn, would strengthen the $\mathrm{C}-\mathrm{O}$ stretch bond and increase its stretch frequency. Indeed, the C-O stretch frequency of $1957 \mathrm{~cm}^{-1}$, as seen in Figure $2 \mathrm{~b}$ is higher than the $1951.1 \mathrm{~cm}^{-1}$ observed for CO-RuTPP in an Ar matrix at $8 \mathrm{~K}$ [33], and the $1944 \mathrm{~cm}^{-1}$ observed in vacuum at $293 \mathrm{~K}$ [34]. The blueshift of $13 \mathrm{~cm}^{-1}$ corresponds to about $2 \%$ increase of $2 \pi^{*}$ occupation [35,36]. 
A previous DFT calculation indicated that the Ru-Cu distance increases by only $0.1 \AA$ on coordination of CO [24]. While this points to a degree of decoupling of RuTPP from the copper substrate, the substantially lower desorption energy of CO-RuTPP/Cu(110), compared to CO-RuTPP in the gas phase, shows that the decoupling is not as strong as observed for other comparable systems $[23,37]$.

$\mathrm{CO}$ adsorbed directly to $\mathrm{Cu}(110)$ is characterized by a frequency of $2093 \mathrm{~cm}^{-1}$, which is similar to a saturated layer of $\mathrm{CO}$ on $\mathrm{Cu}(110)$ free from RuTPP. The TPD peak shape is also similar to a saturated layer of $\mathrm{CO}$ on $\mathrm{Cu}(110)$, so the local $\mathrm{CO}$ coverage on the remaining free areas of $\mathrm{Cu}(110)$ is relatively high.

Irradiating CO-RuTPP/Cu(110) with a $532 \mathrm{~nm}$ femtosecond laser beam led to a sum frequency signal reduction with time, as shown in Figure 3. The signal can be recovered by increasing $\mathrm{CO}$ partial pressure during irradiation, leading to the conclusion that the cause of the sum frequency signal reduction is $\mathrm{CO}$ desorption. The porphyrin layer was not damaged by the laser pulse, since sum frequency spectra at high CO pressure were stable for several hours. CO is only desorbed from RuTPP, not from $\mathrm{Cu}(110)$, unless the fluence of the pump laser is increased more than fourfold. Broadband $\mathrm{CW}$ light (from an ozone-free $\mathrm{Hg}$ lamp with approximately $2 \mathrm{~W}$ incident power) failed to desorb $\mathrm{CO}$, confirming that this is not a simple photochemical effect, but instead is related to the ultrafast excitation.

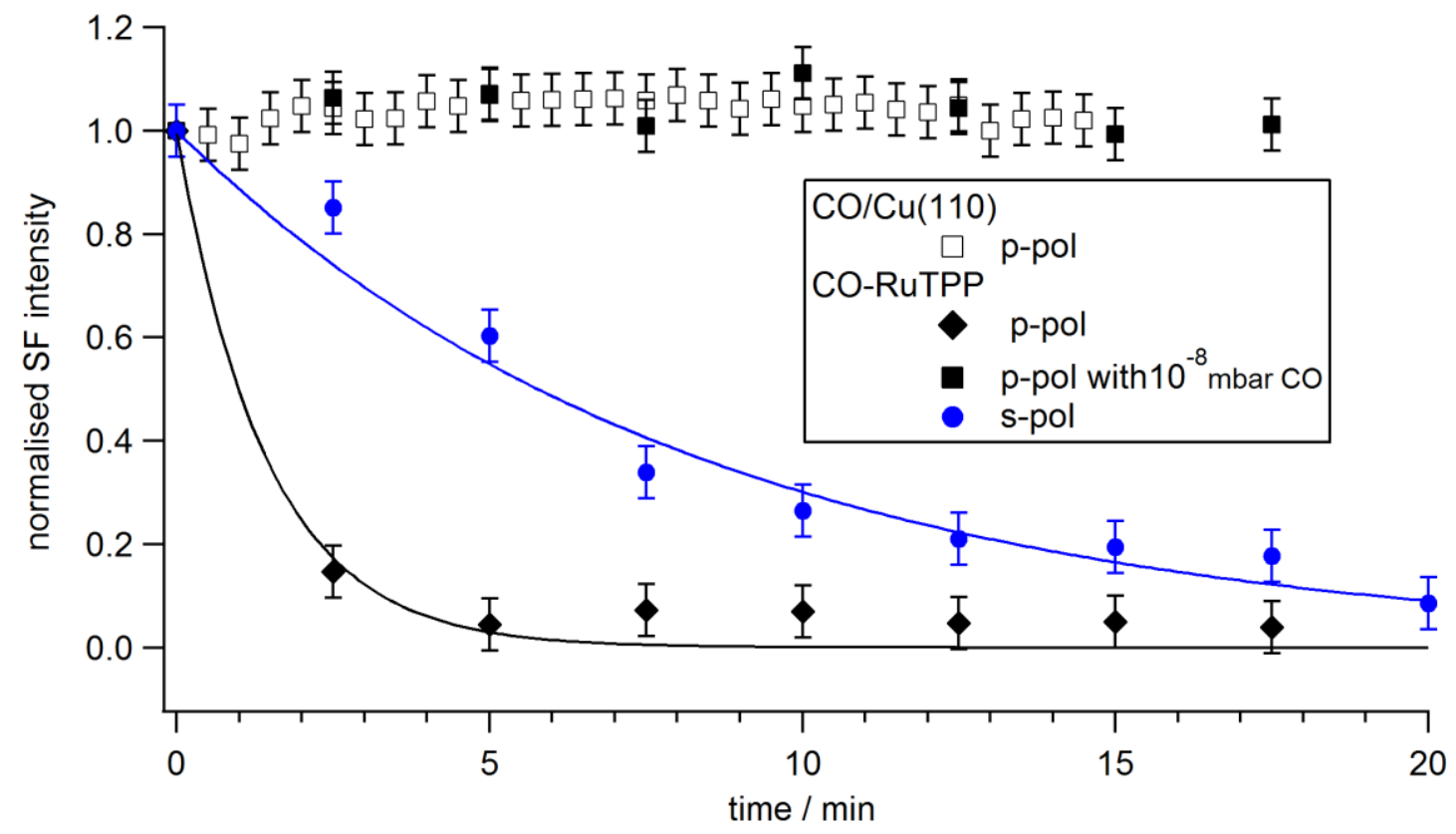

Figure 3. Time evolution of sum frequency intensity under p-polarized fs visible laser (150 fs, $532 \mathrm{~nm}$, $10 \mathrm{~J} / \mathrm{m}^{2}$ ) irradiation. Open squares, diamonds, and closed squares correspond to the integrated sum frequency intensity of $\mathrm{CO} / \mathrm{Cu}(110), \mathrm{CO}-\mathrm{RuTPP}$, and CO-RuTPP with $10^{-8}$ mbar partial CO pressure, respectively. Blue circles show desorption from CO-RuTPP using an s-polarized beam. Lines are drawn to guide the eye.

Changing the polarization of incident light can help to distinguish adsorbate-mediated from substrate-mediated processes if the transition dipole moment of the adsorbate is normal to the surface [38,39]. Figure 3 shows an (approximately) five times faster desorption for p-polarized light than for s-polarized light. At the given incidence angle of $60^{\circ}$ from the surface normal, using the bulk refractive indices for copper, absorbances of 0.52 and 0.23 are expected for $532 \mathrm{~nm} \mathrm{p}$ - and s-polarized light, respectively. Therefore, only a two times faster decay is expected for p-polarized light at the same incident fluence. The polarization dependence indicates that nascent electrons or resonant absorption by adsorbates could play a role; however, we also observe similarly facile laser desorption 
for $800 \mathrm{~nm}(1.55 \mathrm{eV})$ photons, which is more indicative of a hot electron process. Given the band structure of copper, with d-bands around $2 \mathrm{eV}$ below the Fermi level, the cross section for excitation by nascent electrons falls precipitously for photon energies below $2 \mathrm{eV}$ [40]. To fully distinguish adsorbate-mediated from substrate-mediated photodesorption, measurements at multiple incidence angles would be needed. It is worth noting, that this method cannot ascertain the influence of surface parallel transition dipoles (such as the porphyrin Soret band), as this would show the same angular dependence as the substrate absorbance [39].

Observation of $\mathrm{CO}$ photodesorption, therefore, delivers a mixed picture of both adsorbate- and substrate-mediated features, which are difficult to disentangle. As Figure 3 shows, the use of a CO backing pressure allows us to recreate the CO-RuTPP/Cu(110) layer in between laser shots, and permits study of $\mathrm{CO}$ vibrational dynamics under photodesorption conditions.

\subsection{Static Temperature Dependence}

Time-resolved vibrational dynamics, to be discussed in the next section, are normally linked with anharmonic coupling to low frequency modes, which can be derived from changes in the frequency of the $\mathrm{C}-\mathrm{O}$ stretch mode with stepwise changes in substrate temperature. This is shown, in Figure 4, for CO-RuTPP/Cu(110) alongside data from $0.1 \mathrm{ML}$ of $\mathrm{CO} / \mathrm{Cu}(110)$. Both $\mathrm{COs}$ show the same frequency change with temperature. For $\mathrm{CO}$ adsorbed atop metal surfaces, the cause of the $\mathrm{C}-\mathrm{O}$ frequency redshift is normally understood as a displacement of the $\mathrm{CO}$ molecule from the top site to a higher coordination site by the frustrated translation, with higher backdonation into the $\mathrm{CO} 2 \pi^{*}$ orbital and, therefore, a lower IS frequency. The anharmonic coupling constant of the IS to the FT mode, $\Gamma_{14}$, can then be determined from [41]:

$$
v_{1}=v_{1}^{0}-\Gamma_{14}<\mathrm{n}_{4}(\mathrm{~T})>,
$$

where $v_{1}$ and $v_{1}{ }^{0}$ are the frequency of the $\mathrm{C}-\mathrm{O}$ stretch mode at temperature $\mathrm{T}$ and $0 \mathrm{~K}$, respectively, and $<\mathrm{n}_{4}(\mathrm{~T})>$ is the population of the FT mode at temperature T. The FT mode frequency is $28.8 \mathrm{~cm}^{-1}$ for $\mathrm{CO} / \mathrm{Cu}(110)$ [42], which results in an anharmonic coupling constant of IS-FT $\left(\Gamma_{14}\right)$ of $1.0 \pm 0.2 \mathrm{~cm}^{-1}$. Figure 4 includes the results of the linear fit.

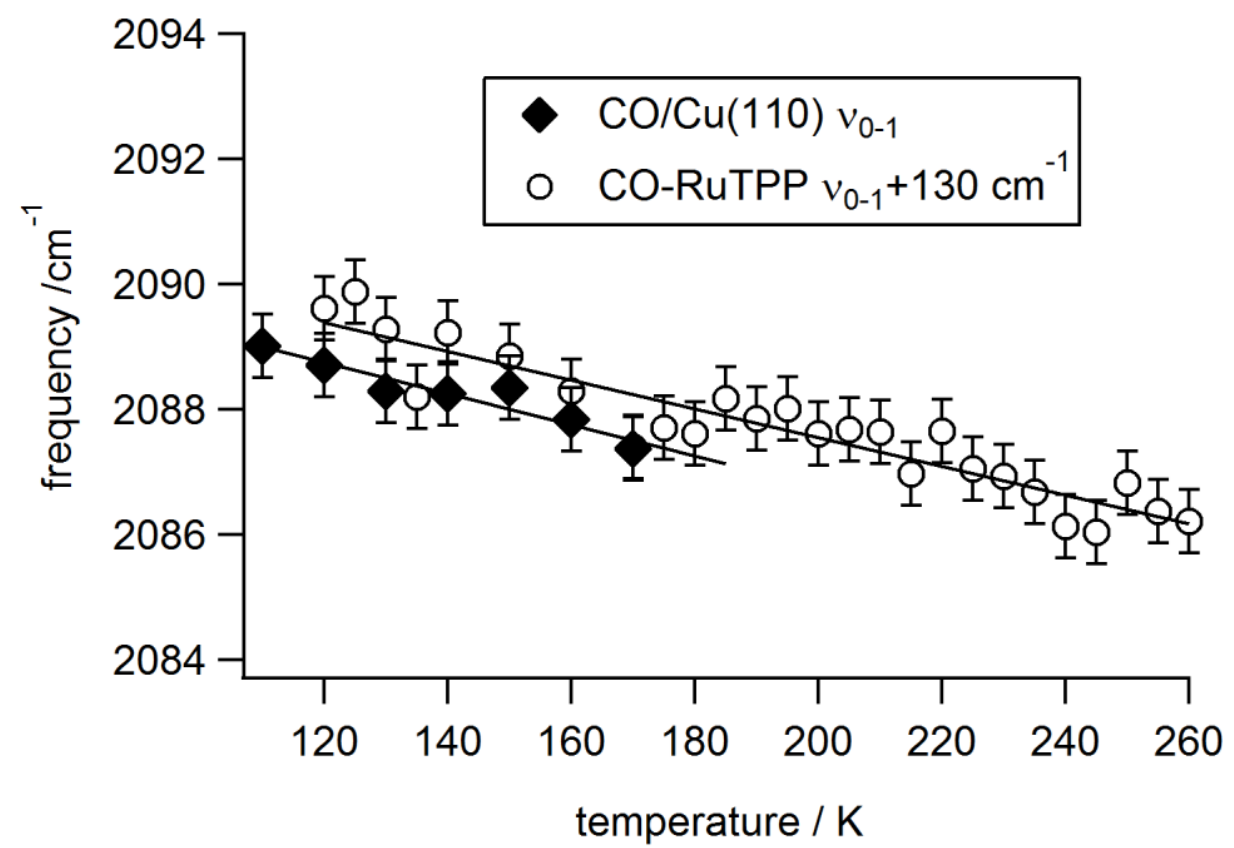

Figure 4. Substrate temperature-dependent frequency shift of the $\mathrm{C}-\mathrm{O}$ stretch mode from $0.1 \mathrm{ML} \mathrm{CO}$ on $\mathrm{Cu}(110)$ and $\mathrm{CO}-\mathrm{RuTPP} / \mathrm{Cu}(110)$ (offset by $130 \mathrm{~cm}^{-1}$ ). Solid lines are the fitting results, using Equation (2). 
The FT mode frequency of CO-RuTPP is not known, but the higher FT frequency of $47 \mathrm{~cm}^{-1}$ for $\mathrm{CO} / \mathrm{Ru}(0001)$ [43] would imply a larger anharmonic coupling constant $\left(1.5 \mathrm{~cm}^{-1}\right)$ to result in the same gradient. Ligand-metalloporphyrin-metal surface systems contain similar low frequency modes to the FT mode of $\mathrm{CO}$ on metal surfaces. Burema et al. reported that the frustrated translational (FT) mode of $\mathrm{NO}$ on CoTPP $/ \mathrm{Ag}(111)$ is around $80-100 \mathrm{~cm}^{-1}$ [44], which is in a similar energy range to the FT mode of $\mathrm{CO}$ and $\mathrm{NO}$ atop metal surfaces. In addition, there are many other low frequency modes in CO-RuTPP since this molecule contains 81 atoms, although we are unable to determine which particular low frequency modes of RuTPP would contribute to the present observation. The similarity of the gradients (in Figure 4) suggests that low frequency modes in CO-RuTPP couple with phonons in a similar way to $\mathrm{CO} / \mathrm{Cu}(110)$, and cause a redshift of the $\mathrm{C}-\mathrm{O}$ stretch by displacement of $\mathrm{CO}$ from atop the ruthenium atom. A possible nearby high coordination site is the bridge site between the ruthenium atom and the nitrogen atom of an imine, which has been observed for CO-CoTPP/Ag(111) [45]. Alternatively, CO-Ru could translate together, with respect to the copper surface; that is, the ruthenium atom moves away from its short bridge site [24], which can reduce the Ru-Cu hybridization, resulting in an increase of backdonation from Ru to CO. Phonon coupling also causes linewidth broadening, due to vibrational dephasing. However, the linewidth of the $\mathrm{C}-\mathrm{O}$ stretch mode of CO-RuTPP remains constant, at $11 \pm 1 \mathrm{~cm}^{-1}$ over the observed temperature range. This indicates that the dephasing contribution is smaller for $\mathrm{CO}$ on $\mathrm{RuTPP} / \mathrm{Cu}(110)$ than for $\mathrm{CO} / \mathrm{Cu}(110)$, and could possibly be masked by the inhomogeneity of the $\mathrm{CO}$ layer.

Slow variation of temperature, therefore, indicates that the anharmonic coupling to low frequency modes is not changed significantly by the introduction of RuTPP.

\subsection{Ultrafast Dynamics}

To gain further insight into the laser-induced desorption, electron-vibration coupling was studied by visible pump-sum frequency probe spectroscopy. The experiments were performed at high CO partial pressures of $\sim 10^{-8}$ mbar, to avoid any change in CO coverage by laser-induced desorption. Figure 5 a shows the frequency shift of the $\mathrm{C}-\mathrm{O}$ stretch mode, induced by $532 \mathrm{~nm}$ pump pulses at fluences of 9 and $13.5 \mathrm{~J} / \mathrm{m}^{2}$. The black circles in Figure 5 show the corresponding data from $\mathrm{CO}$ adsorbed in-between RuTPP molecules on $\mathrm{Cu}(110)$, together with the simulated frequency shift, derived from Carpene's modified two temperature model [46]. In the case of $\mathrm{CO}$ adsorbed in between RuTPP molecules, the transient is similar to those recorded for high coverages of $\mathrm{CO} / \mathrm{Cu}(110)$ [19]. As stated above, both TPD peak shape and C-O frequency suggest that the local coverage of CO adsorbed on sites not covered by RuTPP must be close to saturation. The transient frequency shifts for CO adsorbed on copper and RuTPP are similar at long delay times, where electrons, adsorbates, and phonons have reached thermal equilibrium. This agrees with the static temperature dependence of the C-O stretch, shown in Figure 4.

The transients are very different though at short delay times, less than $5 \mathrm{ps}$. At low fluence, the CO-RuTPP transient exhibits pure coupling to the phonon bath, which gradually heats up during the first few picoseconds. A fast transient, caused by coupling to hot electrons, only appears with increasing fluence, as shown in Figure 5 b,c. Unusually, the C-O frequency shifts to the blue. To test whether the transients were caused by nascent electrons or hot electrons, we varied the pump wavelength. As Figure 6 shows, transients for pump wavelengths of $532 \mathrm{~nm}(2.33 \mathrm{eV})$ and $800 \mathrm{~nm}$ $(1.55 \mathrm{eV})$ are similar for both $\mathrm{CO}$ adsorbed on RuTPP and $\mathrm{Cu}(110)$. The absorbed fluences at the different wavelengths were adjusted to the same value by monitoring the effect on $\mathrm{CO} / \mathrm{Cu}(110)$ (without adsorbed RuTPP) at long delay times, where the effect is purely thermal. Transients with a $400 \mathrm{~nm}(3.1 \mathrm{eV})$ pump were also recorded, but we could not achieve a high enough fluence to cause a clear blue shift around zero delay. Since $1.55 \mathrm{eV}$ photons produce similar transients to $2.33 \mathrm{eV}$ photons, the frequency blue-shift is most likely caused by hot electrons and the copper d-states, starting at $2 \mathrm{eV}$ below the Fermi level, are not involved in the transition. A direct contribution of CO-RuTPP is equally unlikely, as this shows an absorbance maximum around $530 \mathrm{~nm}(\sim 2.3 \mathrm{eV})$ [47]. 


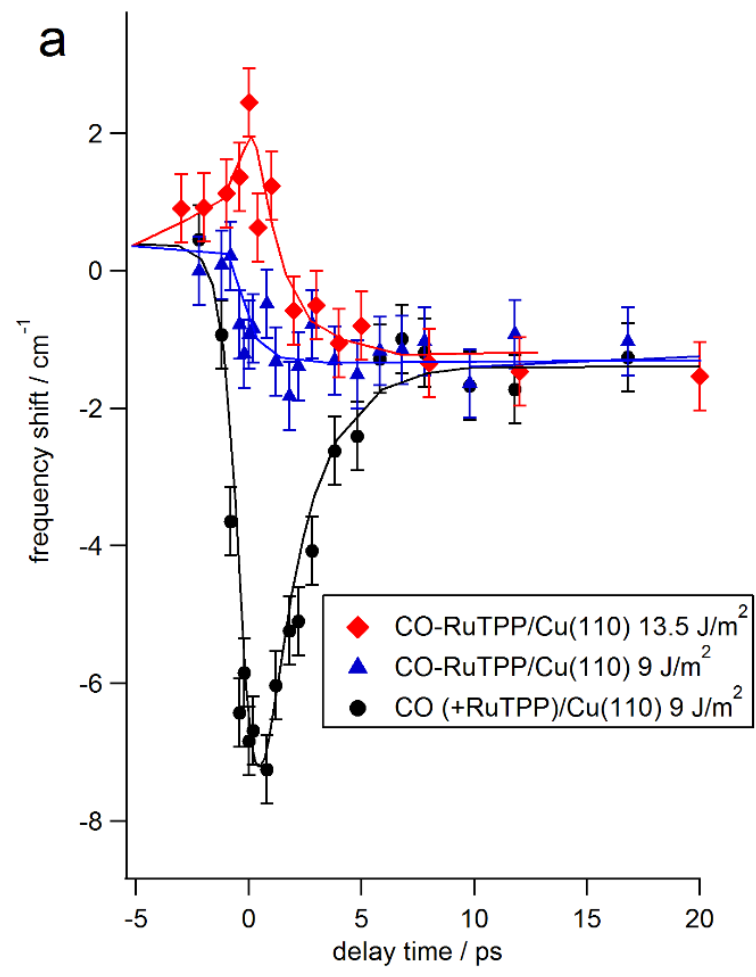

b

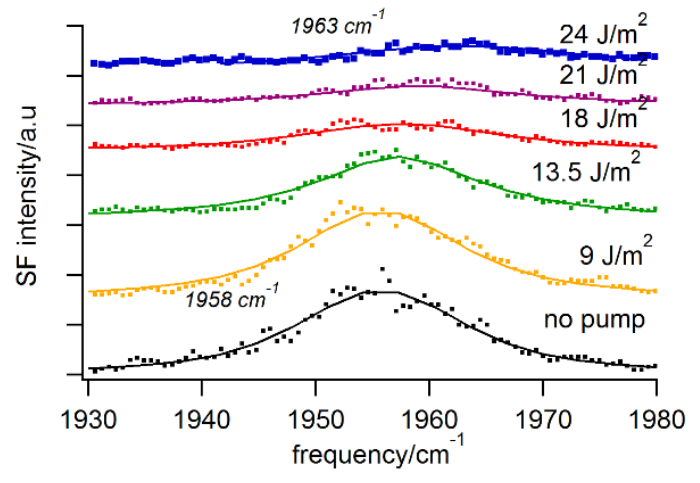

Figure 5. (a) Transient pump induced changes in the C-O stretch frequency of CO-RuTPP and $\mathrm{CO} / \mathrm{Cu}(110)$ for two pump beam fluences (532 nm, p-polarized). Black line calculated as described in the text, blue and red lines to guide the eye. (b) Pump fluence-dependent changes in the CO-RuTPP spectra at zero pump-probe delay time. (c) Frequency shift of CO-RuTPP as a function of pump fluence.

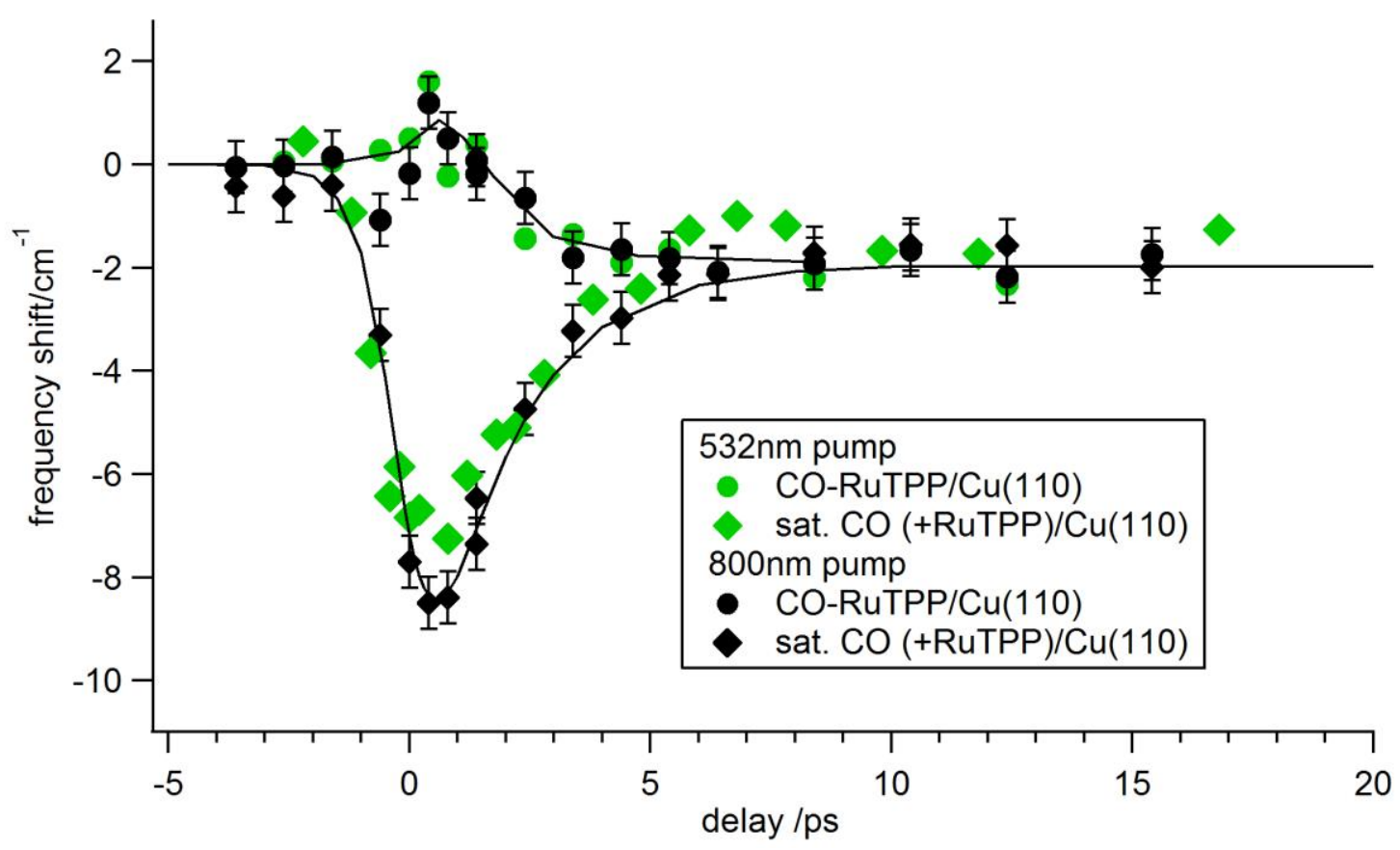

Figure 6. Transient pump induced changes in the $\mathrm{C}-\mathrm{O}$ stretch frequency of $\mathrm{CO}-\mathrm{RuTPP}$ and $\mathrm{CO} / \mathrm{Cu}(110)$ for p-polarized $532 \mathrm{~nm}$ and $800 \mathrm{~nm}$ pump beams with the same fluence of $\sim 13.5 \mathrm{~J} / \mathrm{m}^{2}$. Data acquired under $10^{-8}$ mbar CO partial pressure. 


\section{Discussion}

The introduction of a RuTPP layer onto $\mathrm{Cu}(110)$ changed the ultrafast dynamics of $\mathrm{CO}$ drastically. Femtosecond laser pulses were seen to desorb CO easily from RuTPP, even though the desorption energy from RuTPP was higher than from $\mathrm{Cu}(110)$. The typical redshift of the internal stretch disappeared at short delay times and was replaced by a blue shift at a higher pump fluence. The femtosecond-induced desorption had characteristics of both nascent as well as hot electrons, while the vibrational dynamics seemed to be driven by hot electrons alone. This is not necessarily a contradiction - if only a small fraction of the molecules is in a precursor state to desorption, then the sum frequency spectrum will be dominated by molecules adsorbed on a hot surface, as discussed by others [4].

The frequency blue shift of the internal stretch in the 1-2 ps delay time range, the relevant delay range for desorption, is unusual in pump-probe studies of $\mathrm{CO}$. Inoue et al. reported, for $\mathrm{CO} / \mathrm{Pt}(111)$ under desorption conditions, a very fast redshift of the internal stretch, followed by a reverse (i.e., blue) shift [11]. A possible reason is that the pump pulse excites the adsorbed $\mathrm{CO}$ enough to initially diffuse across the surface, where it collides with other $\mathrm{CO}$ molecules, thus transferring lateral to normal momentum, resulting in an excitation of the surface- $\mathrm{CO}$ vibration and thus a frequency blueshift. A similar picture was derived from ultrafast electronic spectroscopy on $\mathrm{CO} / \mathrm{Ru}(0001)$ [9], which showed evidence for an intermediate state prior to desorption on a picosecond time scale. This precursor state would have a weaker Ru-CO bond and could, thus, show a C-O blueshift, but is hidden in sum frequency spectra, as explained above. The frequency redshift of the $\mathrm{C}-\mathrm{O}$ stretch mode of CO-RuTPP, observed with long delay times, is purely thermal and indicates a very small temperature increase $(\sim 40 \mathrm{~K})$, which is too low to cause desorption.

We will, first, discuss the frequency blueshift in the light of established models, such as change of adsorption site or anharmonic coupling with low frequency vibrational modes.

The possibility of $\mathrm{CO}$ moving to another adsorption site has been discussed in the ultrafast photo-decarboxylation of CO-protein complexes [25-28]. A potential intermediate site of $\mathrm{CO}$ on the RuTPP/Cu(110) surface could be a Ru-N (imine) bridge site, as observed for CoTPP/Ag(111) [45]. However, such a bridge site occupation by $\mathrm{CO}$ was not observed, even at $4.7 \mathrm{~K}$ during STM imaging [24]. Moreover, occupying this bridge site is expected to show a frequency redshift.

In the original anharmonic coupling model [41], frequency changes observed following ultrafast excitation were generally expected to occur with the same sign as those observed by step-wise heating. For singly-coordinated CO, for which the most detailed data are available (e.g., [4,5,41,48]), the internal stretch frequency is generally seen to decrease as it couples anharmonically to the FT, which moves CO from an atop to a multiply coordinated site, which increases backdonation and reduces the frequency. Bridge site $\mathrm{CO}$, however, is thought to anharmonically couple to different low frequency modes, which might reduce the overlap between $2 \pi^{*}$ and metal orbitals, thus causing a blue shift. Persson and Ryberg analyzed the static temperature dependence of the C-O stretch mode of $\mathrm{CO} / \mathrm{Ni}(111)$ [49,50], showing that the redshift of atop $\mathrm{CO}$ is due to coupling to the FT and the blueshift of bridge site $\mathrm{CO}$ is due to coupling to the FR. Cook et al., similarly, detected a blueshift of the bridge site CO on $\operatorname{Pd}(100)$ with increasing temperature, but excluded anharmonic coupling to the FR and, instead, attributed it to multiphonon coupling [51]. The vibrational dynamics of $\mathrm{CO}$ on palladium has only been studied on $\operatorname{Pd}$ nanoclusters [18], and appears to show a frequency redshift-not the blueshift seen on $\operatorname{Pd}(100)$. Such a reversal of sign between slow and ultrafast heating could indicate a change in the vibrational mode that the internal stretch couples to. In our case, switching to coupling with the FR (i.e., bending of the $\mathrm{C}-\mathrm{O}$ bond from the surface normal) could cause a frequency blue shift, due to the reduction of the backdonation from the metal d-orbital to the $\mathrm{CO} 2 \pi^{*}$ orbital, as observed for heme proteins [52]. Bending of $\mathrm{CO}$ by as much as $25^{\circ}$ can take place with an energy input of $0.09 \mathrm{eV}$ or less [53]. Thus, it is feasible that hot electrons/holes could induce bending of $\mathrm{CO}$ on $\mathrm{RuTPP} / \mathrm{Cu}(110)$, which would cause a transient blueshift. 
Ueba and Persson extended the anharmonic coupling model by adding intermode coupling between FR and FT modes [6], as coupling to the FT alone was not sufficient to model vibrational transients when CO is diffusing [8] or desorbing [4]. In this model, both low frequency modes couple to hot electrons with different rates, but also couple to each other.

This extended model has been used by us, previously, to explain why vibrational transients of $\mathrm{CO} / \mathrm{Cu}(110)$ show stronger coupling to hot electrons with increasing $\mathrm{CO}$ coverage [19]. The degree of coupling is thought to change with coverage because $\mathrm{CO}$ coverage increases charge density around the carbon atom. This produces a stronger coupling between FR and hot electrons, and the FT-FR intermode coupling then generates a stronger redshift. This interpretation is supported by Helium atom scattering for $\mathrm{CO}$ on $\mathrm{Cu}(100)$, which also found a gradual increase in coupling between $\mathrm{FT}$ and FR modes with increasing $\mathrm{CO}$ coverage, as neighboring $\mathrm{CO}$ molecules led to a low-frequency motion that was more wagging- than translation-like [54]. CO-RuTPP at $0.04 \mathrm{ML}$ has a coverage that is roughly half the value of the lowest coverage transients, measured previously on $\mathrm{Cu}(110)$ for $0.1 \mathrm{ML}$. These showed a maximum redshift of $3 \mathrm{~cm}^{-1}$ at a short delay time, for a comparable fluence as the one used in Figure 5a. It is, therefore, conceivable that the transient measured at 0.04 ML CO-RuTPP could show even less of a redshift at short delay times, although the change in coupling times with coverage observed on $\mathrm{Cu}(110)$ suggests that the difference would not be large. The redshift could be further reduced, if the intermode coupling between FT and FR is very different for $\mathrm{CO}$ on $\mathrm{Cu}(110)$ compared to $\mathrm{CO}$ on RuTPP. This is feasible: Since the macrocycle is relatively flat and the phenyl rings are relatively far away from $\mathrm{CO}$ adsorbed in the center, the low frequency motions of $\mathrm{CO}$ might acquire a much more harmonic character than on a metal surface. This could drastically reduce FT-FR intermode coupling, explaining the lack of a redshift at lower fluences. As the fluence increases, direct coupling of the internal stretch to a different low frequency mode might then become possible, as discussed above. Since both a bending of $\mathrm{CO}$, as induced by FR excitation, or a lengthening of the Ru-CO bond, as induced by external stretch excitation, could lead to a blueshift, and since both external modes have relatively similar frequencies [55], it would be difficult though to deduce which mode is involved from the transients alone.

Overall, it is possible to explain the cause of the transients by weaker anharmonic coupling between frustrated rotation and translation and stronger anharmonic coupling between frustrated rotation and internal stretch. Nevertheless, this just shifts the unexplained cause from the observed transient to the degree of anharmonic coupling.

A more promising approach has recently emerged from theory $[14,15]$. Novko et al. saw the influence of two different mechanisms in calculated ultrafast transients of $\mathrm{CO} / \mathrm{Cu}(100)$. First, nonadiabatic coupling $(\mathrm{NC})$ between the internal stretch and hot electrons is caused by charge transfer to the $\mathrm{CO} 2 \pi^{*}$, which softens the $\mathrm{C}-\mathrm{O}$ bond and occurs when the electron bath is much hotter than the phonon bath. Such a bond softening by charge transfer was proposed, previously, as a possible origin of the fast transients of $\mathrm{NO} / \operatorname{Ir}(111)$ [56]. Charge transfer from a hot electron bath would explain why we see no significant dependence on pump wavelength, as shown in Figure 6 . The influence of a charge transfer mechanism could be significantly reduced if the $\mathrm{CO} 2 \pi^{*}$ shifts up in energy. This is expected, as the $2 \pi^{*}$ state has been found at $4 \mathrm{eV}$ above $\mathrm{E}_{\mathrm{F}}$ for low $\mathrm{CO}$ coverages on $\mathrm{Ru}(001)$ [57], but at only $1.9 \mathrm{eV}$ for low $\mathrm{CO}$ coverages on $\mathrm{Cu}(100)$ [58]. The second mechanism, electron-mediated phonon-phonon coupling, is caused by electron-hole pairs, which can bridge the energy gap between the IS, coherently excited by the infrared probe pulse and all the vibrational modes available in the system. In this mechanism, coupling to the incoherent IS initially dominates, while, at later times, the influence of FR, FT, and surface phonon modes is felt. This mechanism is predicted to lead to a blue shift when coupling to hot electrons, although the blueshift is much weaker than the redshift caused by charge transfer from hot electrons. For CO-RuTPP, the low frequency RuTPP modes could provide another reservoir of low-frequency vibrational modes to couple to, which, alongside the suppression of the NC mechanism, could lead to an observable distinct blueshift. The model can also easily explain the coverage-dependent nonadiabacity of $\mathrm{CO} / \mathrm{Cu}(110)$, without resorting to intermode coupling - the 
$2 \pi^{*}$ states broaden with coverage which would increase the NC contribution and, thus, increase the redshift at higher coverage.

This model is in line with other theoretical approaches, which have shown the importance of low-frequency surface phonons acting on the same timescale as electron-hole pairs for $\mathrm{CO} / \mathrm{Ru}(001)$ [16], and increased energy transfer from hot electrons into adsorption sites with higher local density of states [59].

Finally, we address the question why we observe facile laser desorption of CO from RuTPP when thermal desorption implies a higher binding energy, compared to $\mathrm{Cu}(110)$. This becomes feasible if desorption is caused by transfer of electrons or holes into states which do not exist on $\mathrm{Cu}(110)$ alone. Prime candidates would be the RuTPP HOMO at $\mathrm{E}_{\mathrm{F}}-0.8 \mathrm{eV}$ and the $\mathrm{CO}$-induced band around the Fermi level of CO-RuTPP/Cu(110) (which likely arises from $\mathrm{d}_{\mathrm{z} 2}$ and $\mathrm{p}_{\mathrm{z}}$ character around the $\mathrm{C}$ atom) observed by scanning tunneling spectroscopy [24]. If both bands were involved, then the RuTPP HOMO might be responsible for an adsorbate-mediated character of the photodesorption, while the CO-induced state near $\mathrm{E}_{\mathrm{F}}$ would be sensitive to the hot electron distribution [60]. Clearly, more detailed desorption experiments are required to answer this question fully.

\section{Conclusions}

Electron-vibration coupling of $\mathrm{CO}$ on the RuTPP-covered $\mathrm{Cu}(110)$ surface was studied by pump-probe SFG under photodesorption conditions. Femtosecond visible pump-sum frequency probe spectroscopy revealed that coupling with hot electrons was significantly altered by introducing the RuTPP monolayer, as the frequency redshift, typical for the internal stretch of $\mathrm{CO}$ adsorbed on metal surfaces, disappears and is replaced by a blueshift at short delay times. Interpretation within the established framework of intermode coupling between IS, FR, and FT is problematic. Instead, we suggest that the upshift of the $\mathrm{CO} 2 \pi^{*}$ state on RuTPP suppresses the frequency redshift caused by charge transfer from hot electrons and reveals the blueshift caused by electron-mediated coupling between the coherently excited internal stretch and all other low frequency modes in the system, as recently proposed in the electron-mediated phonon-phonon coupling mechanism.

Author Contributions: Data curation, T.O.; Formal analysis, T.O.; Investigation, T.O.; Supervision, Y.K., R.R., and H.A.; Writing-original draft, T.O.; Writing-review \& editing, H.A.

Acknowledgments: We thank Michael Higlett for providing us with the Matlab code used in the calculation of hot electron and phonon temperatures [61].

Conflicts of Interest: The authors declare no conflict of interest.

\section{References}

1. Arnolds, H. Vibrational dynamics of adsorbates-Quo vadis? Prog. Surf. Sci. 2011, 86, 1-40. [CrossRef]

2. Arnolds, H.; Bonn, M. Ultrafast surface vibrational dynamics. Surf. Sci. Rep. 2010, 65, 45-66. [CrossRef]

3. Kraack, J.P.; Hamm, P. Surface-Sensitive and Surface-Specific Ultrafast Two-Dimensional Vibrational Spectroscopy. Chem. Rev. 2017, 117, 10623-10664. [CrossRef] [PubMed]

4. Bonn, M.; Hess, C.; Funk, S.; Miners, J.H.; Persson, B.N.J.; Wolf, M.; Ertl, G. Femtosecond surface vibrational spectroscopy of CO adsorbed on Ru(001) during desorption. Phys. Rev. Lett. 2000, 84, 4653-4656. [CrossRef] [PubMed]

5. Fournier, F.; Zheng, W.; Carrez, S.; Dubost, H.; Bourguignon, B. Vibrational dynamics of adsorbed molecules under conditions of photodesorption: Pump-probe SFG spectra of CO/Pt(111). J. Chem. Phys. 2004, 121, 4839-4847. [CrossRef] [PubMed]

6. Ueba, H.; Persson, B. Heating of adsorbate by vibrational-mode coupling. Phys. Rev. B 2008, 77, 035413. [CrossRef]

7. Ueba, H.; Persson, B.N.J. Heat transfer between adsorbate and laser-heated hot electrons. J. Phys. Condens. Matter 2008, 20, 224016. [CrossRef]

8. Backus, E.H.; Eichler, A.; Kleyn, A.W.; Bonn, M. Real-time observation of molecular motion on a surface. Science 2005, 310, 1790-1793. [CrossRef] [PubMed] 
9. Dell'Angela, M.; Anniyev, T.; Beye, M.; Coffee, R.; Föhlisch, A.; Gladh, J.; Katayama, T.; Kaya, S.; Krupin, O.; LaRue, J.; et al. Real-time observation of surface bond breaking with an X-ray laser. Science 2013, 339, 1302-1305. [CrossRef] [PubMed]

10. Beye, M.; Anniyev, T.; Coffee, R.; Dell'Angela, M.; Föhlisch, A.; Gladh, J.; Katayama, T.; Kaya, S.; Krupin, O.; Møgelhøj, A.; et al. Selective Ultrafast Probing of Transient Hot Chemisorbed and Precursor States of CO on Ru(0001). Phys. Rev. Lett. 2013, 110, 186101. [CrossRef] [PubMed]

11. Inoue, K.; Watanabe, K.; Matsumoto, Y. Instantaneous vibrational frequencies of diffusing and desorbing adsorbates: CO/Pt(111). J. Chem. Phys. 2012, 137, 024704. [CrossRef] [PubMed]

12. Inoue, K.; Watanabe, K.; Sugimoto, T.; Matsumoto, Y.; Yasuike, T. Disentangling Multidimensional Nonequilibrium Dynamics of Adsorbates: CO Desorption from Cu(100). Phys. Rev. Lett. 2016, 117, 186101. [CrossRef] [PubMed]

13. Alducin, M.; Díez Muiño, R.; Juaristi, J.I. Non-adiabatic effects in elementary reaction processes at metal surfaces. Prog. Surf. Sci. 2017, 92, 317-340. [CrossRef]

14. Novko, D.; Alducin, M.; Blanco-Rey, M.; Juaristi, J.I. Effects of electronic relaxation processes on vibrational linewidths of adsorbates on surfaces: The case of CO/Cu(100). Phys. Rev. B 2016, 94, 224306. [CrossRef]

15. Novko, D.; Tremblay, J.C.; Alducin, M.; Juaristi, J.I. Ultrafast Transient Dynamics of Adsorbates on Surfaces Deciphered: The Case of CO on Cu(100). Phys. Rev. Lett. 2019, 122, 016806. [CrossRef]

16. Scholz, R.; Floß, G.; Saalfrank, P.; Füchsel, G.; Lončarić, I.; Juaristi, J.I. Femtosecond-laser induced dynamics of $\mathrm{CO}$ on $\mathrm{Ru}(0001)$ : Deep insights from a hot-electron friction model including surface motion. Phys. Rev. B 2016, 94, 165447. [CrossRef]

17. Ghalgaoui, A.; Horchani, R.; Wang, J.J.; Ouvrard, A.; Carrez, S.; Bourguignon, B. Identification of Active Sites in Oxidation Reaction from Real-Time Probing of Adsorbate Motion over Pd Nanoparticles. J. Phys. Chem. Lett. 2018, 9, 5202-5206. [CrossRef] [PubMed]

18. Ghalgaoui, A.; Ouvrard, A.; Wang, J.J.; Carrez, S.; Zheng, W.Q.; Bourguignon, B. Electron to Adsorbate Energy Transfer in Nanoparticles: Adsorption Site, Size, and Support Matter. J. Phys. Chem. Lett. 2017, 8 , 2666-2671. [CrossRef] [PubMed]

19. Omiya, T.; Arnolds, H. Coverage dependent non-adiabaticity of CO on a copper surface. J. Chem. Phys. 2014, 141, 214705. [CrossRef] [PubMed]

20. Hong, S.-Y.; Xu, P.; Camillone, N.R.; White, M.G.; Camillone, N., III. Adlayer structure dependent ultrafast desorption dynamics in carbon monoxide adsorbed on Pd (111). J. Chem. Phys. 2016, 145, 014704. [CrossRef] [PubMed]

21. Szymanski, P.; Harris, A.L.; Camillone, N., III. Temperature-Dependent Femtosecond Photoinduced Desorption in CO/Pd(111). J. Phys. Chem. A 2007, 111, 12524-12533. [CrossRef] [PubMed]

22. Levine, L.M.A.; Holten, D. Axial-ligand control of the photophysical behavior of ruthenium(II) tetraphenyl-and octaethylporphyrin: Contrasting properties of metalloporphyrin (.pi.,.pi.*) and (d,.pi. $\left.{ }^{*}\right)$ excited states. J. Phys. Chem. 1988, 92, 714-720. [CrossRef]

23. Hieringer, W.; Flechtner, K.; Kretschmann, A.; Seufert, K.; Auwarter, W.; Barth, J.V.; Gorling, A.; Steinruck, H.P.; Gottfried, J.M. The surface trans effect: Influence of axial ligands on the surface chemical bonds of adsorbed metalloporphyrins. J. Am. Chem. Soc. 2011, 133, 6206-6222. [CrossRef] [PubMed]

24. Omiya, T.; Poli, P.; Arnolds, H.; Raval, R.; Persson, M.; Kim, Y. Desorption of CO from individual ruthenium porphyrin molecules on a copper surface via an inelastic tunnelling process. Chem. Commun. 2017, 53, 6148-6151. [CrossRef] [PubMed]

25. Nuernberger, P.; Lee, K.F.; Bonvalet, A.; Bouzhir-Sima, L.; Lambry, J.C.; Liebl, U.; Joffre, M.; Vos, M.H. Strong Ligand-Protein Interactions Revealed by Ultrafast Infrared Spectroscopy of CO in the Heme Pocket of the Oxygen Sensor FixL. J. Am. Chem. Soc. 2011, 133, 17110-17113. [CrossRef] [PubMed]

26. Nuernberger, P.; Lee, K.F.; Bonvalet, A.; Vos, M.H.; Joffre, M. Multiply Excited Vibration of Carbon Monoxide in the Primary Docking Site of Hemoglobin Following Photolysis from the Heme. J. Phys. Chem. Lett. 2010, 1, 2077-2081. [CrossRef]

27. Van Wilderen, L.J.G.W.; Key, J.M.; Van Stokkum, I.H.M.; van Grondelle, R.; Groot, M.L. Dynamics of carbon monoxide photodissociation in bradyrhizobium japonicum FixL probed by picosecond midinfrared spectroscopy. J. Phys. Chem. B 2009, 113, 3292-3297. [CrossRef] [PubMed]

28. Lim, M.H.; Jackson, T.A.; Anfinrud, P.A. Ultrafast rotation and trapping of carbon monoxide dissociated from myoglobin. Nat. Struct. Biol. 1997, 4, 209-214. [CrossRef] [PubMed] 
29. Lagutchev, A.; Hambir, S.A.; Dlott, D.D. Nonresonant background suppression in broadband vibrational sum-frequency generation spectroscopy. J. Phys. Chem. C 2007, 111, 13645-13647. [CrossRef]

30. Donovan, P.; Robin, A.; Dyer, M.S.; Persson, M.; Raval, R. Unexpected Deformations Induced by Surface Interaction and Chiral Self-Assembly of CoII-Tetraphenylporphyrin (Co-TPP) Adsorbed on Cu(110): A Combined STM and Periodic DFT Study. Chem. Eur. J. 2010, 16, 11641-11652. [CrossRef] [PubMed]

31. Woodruff, D.P.; Hayden, B.E.; Prince, K.; Bradshaw, A.M. Dipole coupling and chemical shifts in IRAS of CO adsorbed on $\mathrm{Cu}(110)$. Surf. Sci. 1982, 123, 397-412. [CrossRef]

32. Shafizadeh, N.; Boye-Peronne, S.; Soorkia, S.; de Miranda, B.K.C.; Garcia, G.A.; Nahon, L.; Chen, S.F.; de la Lande, A.; Poisson, L.; Soep, B. The surprisingly high ligation energy of CO to ruthenium porphyrins. Phys. Chem. Chem. Phys. 2018, 20, 11730-11739. [CrossRef] [PubMed]

33. Krim, L.; Sorgues, S.; Soep, B.; Shafizadeh, N. Infrared spectra of RuTPP, RuCOTPP, and Ru(CO)2TPP isolated in solid argon. J. Phys. Chem. A 2005, 109, 8268-8274. [CrossRef] [PubMed]

34. Azizyan, A.S.; Kurtikyan, T.S.; Martirosyan, G.G.; Ford, P.C. Tracking reactive intermediates by FTIR monitoring of reactions in low-temperature sublimed solids: Nitric oxide disproportionation mediated by ruthenium(II) carbonyl porphyrin Ru(TPP)(CO). Inorg. Chem. 2013, 52, 5201-5205. [CrossRef] [PubMed]

35. Baerends, E.J.; Ros, P. Evaluation of the LCAO Hartree-Fock-Slater method: Applications to transition-metal complexes. Int. J. Quantum Chem. 1978, 14, 169-190. [CrossRef]

36. Hoffmann, F.M. Infrared reflection-absorption spectroscopy of adsorbed molecules. Surf. Sci. Rep. 1983, 3, 107-192. [CrossRef]

37. Isvoranu, C.; Wang, B.; Ataman, E.; Knudsen, J.; Schulte, K.; Andersen, J.N.; Bocquet, M.-L.; Schnadt, J. Comparison of the Carbonyl and Nitrosyl Complexes Formed by Adsorption of CO and NO on Monolayers of Iron Phthalocyanine on Au(111). J. Phys. Chem. C 2011, 115, 24718-24727. [CrossRef]

38. Zhou, X.L.; Zhu, X.Y.; White, J.M. Photochemistry at adsorbate/metal interfaces. Surf. Sci. Rep. 1991, 13, 73-220. [CrossRef]

39. Richter, L.J.; Buntin, S.A.; King, D.S.; Cavanagh, R.R. Constraints on the use of polarization and angle-of-incidence to characterize surface photoreactions. Chem. Phys. Lett. 1991, 186, 423-426. [CrossRef]

40. García Rey, N.; Arnolds, H. Hot hole-induced dissociation of NO dimers on a copper surface. J Chem Phys 2011, 135, 224708. [CrossRef] [PubMed]

41. Germer, T.A.; Stephenson, J.C.; Heilweil, E.J.; Cavanagh, R.R. Picosecond time-resolved adsorbate response to substrate heating: Spectroscopy and dynamics of $\mathrm{CO} / \mathrm{Cu}(100)$. J. Chem. Phys. 1994, 101, 1704-1716. [CrossRef]

42. Braun, J.; Weckesser, J.; Ahner, J.; Mocuta, D.; Yates, J.T., Jr.; Wöll, C. The frustrated translational mode of CO on $\mathrm{Cu}(110)$ : Azimuthal anisotropy studied by helium atom scattering-A comparison with time-of-flight electron stimulated desorption of ion angular distribution measurements. J. Chem. Phys. 1998, 108, 5161-5164. [CrossRef]

43. Braun, J.; Kostov, K.L.; Witte, G.; Wöll, C. CO overlayers on Ru(0001) studied by helium atom scattering: Structure, dynamics, and the influence of coadsorbed H and O. J. Chem. Phys. 1997, 106, 8262-8273. [CrossRef]

44. Burema, S.R.; Seufert, K.; Auwärter, W.; Barth, J.V.; Bocquet, M.-L. Probing nitrosyl ligation of surface-confined metalloporphyrins by inelastic electron tunneling spectroscopy. Acs Nano 2013, 7, 5273-5281. [CrossRef] [PubMed]

45. Seufert, K.; Bocquet, M.-L.; Auwärter, W.; Weber-Bargioni, A.; Reichert, J.; Lorente, N.; Barth, J.V. Cis-dicarbonyl binding at cobalt and iron porphyrins with saddle-shape conformation. Nat. Chem. 2011, 3, 114-119. [CrossRef] [PubMed]

46. Carpene, E. Ultrafast laser irradiation of metals: Beyond the two-temperature model. Phys. Rev. B 2006, 74, 024301. [CrossRef]

47. Vogler, A.; Kunkely, H. Photochemistry of biologically important transition metal complexes. II. carbonylpiperidinetetraphenylporphine complexes of iron(II) and ruthenium(II). Ber. Bunsenges. Phys. Chem. 1976, 80, 425-429. [CrossRef]

48. Lane, I.M.; Liu, Z.P.; King, D.A.; Arnolds, H. Ultrafast vibrational dynamics of NO and CO adsorbed on an iridium surface. J. Phys. Chem. C 2007, 111, 14198-14206. [CrossRef]

49. Persson, B.N.J.; Ryberg, R. Brownian motion and vibrational phase relaxation at surfaces: CO on Ni(111). Phys. Rev. B 1985, 32, 3586-3596. [CrossRef] 
50. Persson, B.N.J.; Ryberg, R. Vibrational phase relaxation at surfaces: CO on Ni(111). Phys. Rev. Lett. 1985, 54, 2119-2122. [CrossRef] [PubMed]

51. Cook, J.C.; Clowes, S.K.; McCash, E.M. Reflection absorption IR studies of vibrational energy transfer processes and adsorption energetics. J. Chem. Soc. Faraday Trans. 1997, 93, 2315-2322. [CrossRef]

52. Li, X.Y.; Spiro, T.G. Is bound carbonyl linear or bent in heme proteins? Evidence from resonance Raman and infrared spectroscopic data. J. Am. Chem. Soc. 1988, 110, 6024-6033. [CrossRef] [PubMed]

53. Ghosh, A.; Bocian, D.F. Carbonyl tilting and bending potential energy surface of carbon monoxyhemes. J. Phys. Chem. 1996, 100, 6363-6367. [CrossRef]

54. Graham, A.P.; Hofmann, F.; Toennies, J.P.; Williams, G.P.; Hirschmugl, C.J.; Ellis, J. A high resolution helium atom scattering and far infrared study of the dynamics and the lateral potential energy surface of $\mathrm{CO}$ molecules chemisorbed on $\mathrm{Cu}(001)$. J. Chem. Phys. 1998, 108, 7825-7834. [CrossRef]

55. Hirschmugl, C.; Williams, G.; Hoffmann, F.; Chabal, Y. Adsorbate-substrate resonant interactions observed for $\mathrm{CO}$ on $\mathrm{Cu}(100)$ in the far infrared. Phys. Rev. Lett. 1990, 65, 480-483. [CrossRef] [PubMed]

56. Lane, I.M.; King, D.A.; Liu, Z.-P.; Arnolds, H. Real-time observation of nonadiabatic surface dynamics: The first picosecond in the dissociation of $\mathrm{NO}$ on iridium. Phys. Rev. Lett. 2006, 97, 186105. [CrossRef] [PubMed]

57. Benndorf, C.; Bertel, E.; Dose, V.; Jacob, W.; Memmel, N.; Rogozik, J. An inverse photoemission study of CO adsorption on clean and potassium promoted Ru(001). Surf. Sci. 1987, 191, 455-465. [CrossRef]

58. Rogozik, J.; Scheidt, H.; Dose, V.; Prince, K.C.; Bradshaw, A.M. The 2 $\pi$-derived level in the adsorption system CO/Cu(110). Surf. Sci. Lett. 1984, 145, L481-L487.

59. Backus, E.H.G.; Forsblom, M.; Persson, M.; Bonn, M. Highly efficient ultrafast energy transfer into molecules at surface step sites. J. Phys. Chem. C 2007, 111, 6149-6153. [CrossRef]

60. Avanesian, T.; Christopher, P. Adsorbate specificity in hot electron driven photochemistry on catalytic metal surfaces. J. Phys. Chem. C 2014, 118, 28017-28031. [CrossRef]

61. Garduño-Mejía, J.; Higlett, M.P.; Meech, S.R. Modelling the influence of nonthermal electron dynamics in thin and ultrathin gold films. Chem. Phys. 2007, 341, 276-284. [CrossRef]

(C) 2019 by the authors. Licensee MDPI, Basel, Switzerland. This article is an open access article distributed under the terms and conditions of the Creative Commons Attribution (CC BY) license (http://creativecommons.org/licenses/by/4.0/). 